\title{
Deep brain stimulation macroelectrodes compared to multiple microelectrodes in rat hippocampus
}

\author{
Sharanya Arcot Desai ${ }^{1,2}$, Claire-Anne Gutekunst ${ }^{3}$, Steve M. Potter ${ }^{1,2}{ }^{* t}$ and Robert E. Gross ${ }^{2,3}{ }^{* t}$ \\ ' Laboratory for Neuroengineering, Georgia Institute of Technology, Atlanta, GA, USA \\ ${ }^{2}$ The Wallace H. Coulter Department of Biomedical Engineering, Georgia Institute of Technology, Atlanta, GA, USA \\ ${ }^{3}$ Department of Neurosurgery, Emory University School of Medicine, Atlanta, GA, USA
}

\section{Edited by:}

Laura Ballerini, University of Trieste, Italy

\section{Reviewed by:}

Luca Berdondini, Italian Institute of Technology, Italy

Vassiliy Tsytsarev, University of

Maryland School of Medicine, USA

\section{*Correspondence:}

Steve M. Potter, Laboratory for

Neuroengineering, Georgia Institute of Technology, 313 Ferst Drive,

Atlanta, GA 30332, USA

e-mail: steve.potter@bme.gatech.edu; Robert E. Gross, Department of

Neurosurgery, Emory University School of Medicine, Suite 6329, 101 Woodruff Circle, Atlanta, GA 30322, USA

e-mail:rgross@emory.edu

${ }^{+}$Steve M. Potter and Robert E. Gross have contributed equally to this work.
Microelectrode arrays (wire diameter $<50 \mu \mathrm{m}$ ) were compared to traditional macroelectrodes for deep brain stimulation (DBS). Understanding the neuronal activation volume may help solve some of the mysteries associated with DBS, e.g., its mechanisms of action. We used c-fos immunohistochemistry to investigate neuronal activation in the rat hippocampus caused by multi-micro- and macroelectrode stimulation. At $\pm 1 \mathrm{~V}$ stimulation at $25 \mathrm{~Hz}$, microelectrodes (33 $\mu \mathrm{m}$ diameter) had a radius of activation of $100 \mu \mathrm{m}$, which is $50 \%$ of that seen with $150 \mu \mathrm{m}$ diameter macroelectrode stimulation. Macroelectrodes activated about 5.8 times more neurons than a single microelectrode, but displaced $\sim 20$ times more neural tissue. The sphere of influence of stimulating electrodes can be significantly increased by reducing their impedance. By ultrasonic electroplating (sonicoplating) the microelectrodes with platinum to increase their surface area and reduce their impedance by an order of magnitude, the radius of activation increased by $50 \mu \mathrm{m}$ and more than twice the number of neurons were activated within this increased radius compared to unplated microelectrodes. We suggest that a new approach to DBS, one that uses multiple high-surface area microelectrodes, may be more therapeutically effective due to increased neuronal activation.

Keywords: deep brain stimulation, neuronal activation, immediate early gene (IEG), multielectrode array (MEA), macroelectrodes, hippocampus, electroplating

\section{INTRODUCTION}

While beneficial for neuropsychiatric disorders spanning a wide range (e.g., Parkinson's disease, depression, epilepsy), much remains to be learned about the mechanisms of action of deep brain stimulation (DBS; Kumar etal., 1998; McIntyre et al., 2004b; Mayberg etal., 2005; Greenberg et al., 2006; Perlmutter and Mink, 2006; Volkmann etal., 2006; Benabid et al., 2009). In particular, a greater understanding the spatial extent of influence of electrical stimulation and the factors that determine it is required to optimize the effectiveness and efficiency of DBS.

All clinical DBS electrodes are single macroelectrodes, cylindrical in shape with diameters $\sim 1 \mathrm{~mm}$ and surface areas $\sim 6 \mathrm{~mm}^{2}$, although arrays of multiple smaller electrodes have been proposed. However, stimulation through multielectrode arrays (MEA) of microelectrodes (i.e., microstimulation; Desai et al., 2010) may have advantages when compared to single macroelectrode stimulation (i.e., macrostimulation) for several reasons, especially when stimulating complex structures like the hippocampus, an important locus in the etiology of temporal lobe epilepsy (Velasco et al., 2001, 2007). First, microelectrodes with diameters of 10 s of microns can be specifically targeted toward particular cell layers, which may not be possible with a macroelectrode whose diameter (e.g., $1.27 \mathrm{~mm}$ ) is bigger than these targets. Second, one or a few microelectrodes within a MEA may be stimulated at a time, which would enable spatiotemporal patterns of stimulation not possible with a single macroelectrode. Third, tissue damage by MEAs may be less than that caused by macroelectrodes. The first goal of this study was to compare the volume of tissue activated by multimicroelectrode arrays and single macroelectrodes.

Reducing the impedance of microelectrodes provides several advantages for neural recording, such as reduced stimulation artifact and reduced thermal noise leading to improved signal to noise ratio (Ferguson et al., 2009; Desai et al., 2010). For microstimulation, stimulation amplitude is limited to $1 \mathrm{~V}$ due to the possibility of water hydrolysis, which therefore limits current density and thus stimulation effectiveness (Rozman et al., 2000). Thus, impedance reduction allows for achieving higher currents in both voltage and current-controlled applications at the near-maximum of safe voltages. A second goal of this study was to compare volume of tissue activated with untreated microelectrodes to that attained in electroplated microelectrodes that are coated to reduce impedance (Desai et al., 2010).

Several simulation studies by Grill (1999), McIntyre et al. (2004a), Wei and Grill (2009), Chaturvedi etal. (2010), Butson et al. (2011), and others have estimated the electrical fields and activating functions surrounding electrode tracks, but this needs validation in living neuronal tissue. An excellent study by Histed et al. (2009) used 2-photon calcium imaging to study patterns of cell activation using microelectrodes in the superficial layers of cortex. Although this technique has great temporal 
and spatial resolution, it cannot be used in deep brain structures like thalamus or hippocampus because brain tissue strongly scatters light and imaging becomes impossible beyond a depth of $1 \mathrm{~mm}$ (Helmchen and Denk, 2005). The results from the Histed et al. (2009) study will certainly serve as a guiding point for understanding electrical stimulation interaction with neuronal populations, but cannot be directly translated to other brain regions which have different cytoarchitecture and projection patterns.

c-fos is an immediate early gene which has been used extensively as a metabolic marker to study seizure pathways and neuroanatomical connections, and to analyze neuronal populations activated by a wide range of stimuli including neuroactive drugs and brain stimulation techniques (Dragunow and Faull, 1989; Saryyeva et al., 2011). Transient induction of c-fos mRNA and protein has been reported in several studies following neuronal excitation (Morgan and Curran, 1991). The mRNA reaches peak values at 30-45 min post-stimulation and decays with a halflife of $12 \mathrm{~min}$. c-fos protein synthesis follows mRNA expression and it is turned over with a half-life of about $2 \mathrm{~h}$ (Muller et al., 1984). Given these long activation and decay time scales, this technique lacks temporal resolution. However, it provides single-cell spatial resolution and can be used to visualize and count individual neurons activated by electrical stimulation as shown in Saryyeva et al. (2011) and da Silva et al. (2014). In this study, we used c-fos immunohistochemistry to study neuronal activation caused by DBS in the dorsal hippocampus using macroelectrode, microelectrode, and electroplated microelectrode stimulation.

\section{MATERIALS AND METHODS}

All animal procedures were conducted in accordance with the National Institute of Health Guide for the Care and Use of Laboratory Animals and approved by the Emory University Institutional Animal Care and Use Committee.

Twenty-four rats were used in this study, divided into three groups of 8 . Rats in group 1 had a single macroelectrode $(150 \mu \mathrm{m}$ diameter, Plastics One, VA, USA) aimed toward the CA3 cell layer of the dorsal hippocampus. Rats in groups 2 and 3 were implanted with a microelectrode array (Tucker-Davis Technologies, FL, USA) with $1633-\mu \mathrm{m}$ diameter electrodes arranged in two rows of 8 (Figure 1). Row 1 was targeted toward the CA1 cell layer and row 2 was targeted toward the CA3 cell layer of the dorsal hippocampus. Whereas group 2 had unplated microelectrodes implanted, the microelectrodes in group 3 had their impedances reduced by an order of magnitude by sonicoplating with platinum black (Desai et al., 2010). Sonicoplating (electroplating under ultrasonic vibrations) significantly improves the durability of platinum black on the base metal. Details on this procedure and its effect on recording and stimulation performance of the microelectrode in chronic implants can be found elsewhere (Desai et al., 2010). Shown in Figure 2 are impedance plots of a macroelectrode and microelectrode array before and after electroplating. Since microelectrodes in the MEA were connected in parallel while being stimulated, it was necessary to make sure that the combined impedance of 15 microelectrodes (with and without electroplating) did not fall below $200 \Omega$ since the maximum current delivering capacity of our setup is $\pm 5 \mathrm{~mA}$ and we used $\pm 1 \mathrm{~V}$ voltage controlled stimulation in our study.

\section{SURGERY}

Each rat was anesthetized with 1.5-3\% inhaled isoflurane before receiving a craniectomy over the right dorsal hippocampus. Each rat was then implanted with either a single macroelectrode (group 1 ), an unplated microelectrode array (group 2) or a sonicoplated microelectrode array (group 3). Half the rats in each group received $4 \mathrm{~h}$ of $\pm 1 \mathrm{~V}, 400 \mu \mathrm{s}$ per phase, biphasic square pulses at $25 \mathrm{~Hz}$. Preliminary experiments performed with varying durations of stimulation showed consistently good c-fos expression at $4 \mathrm{~h}$ of stimulation. A recent study which analyzed differences between $25 \mathrm{~Hz}$ and $130 \mathrm{~Hz}$ DBS in the pedunculopontine tegmental nucleus in the rat 6-hydroxydopamine Parkinson's disease model, also
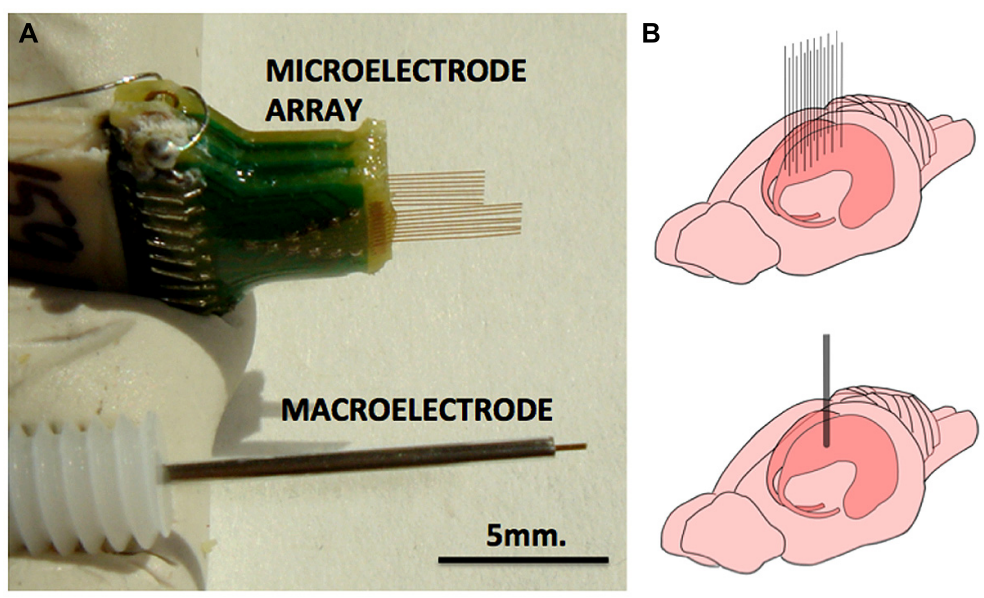

FIGURE 1 | Macroelectrode and microelectrode array used in this study. (A) Pictures of microelectrode array (MEA) and macroelectrode of the type that were used in this study. Each of the 16 electrodes of the MEA measure
$33 \mu \mathrm{m}$ in diameter and the macroelectrode measures $150 \mu \mathrm{m}$. (B) The approximate implantation positions of the MEA and the macroelectrode in the rodent dorsal hippocampus. 


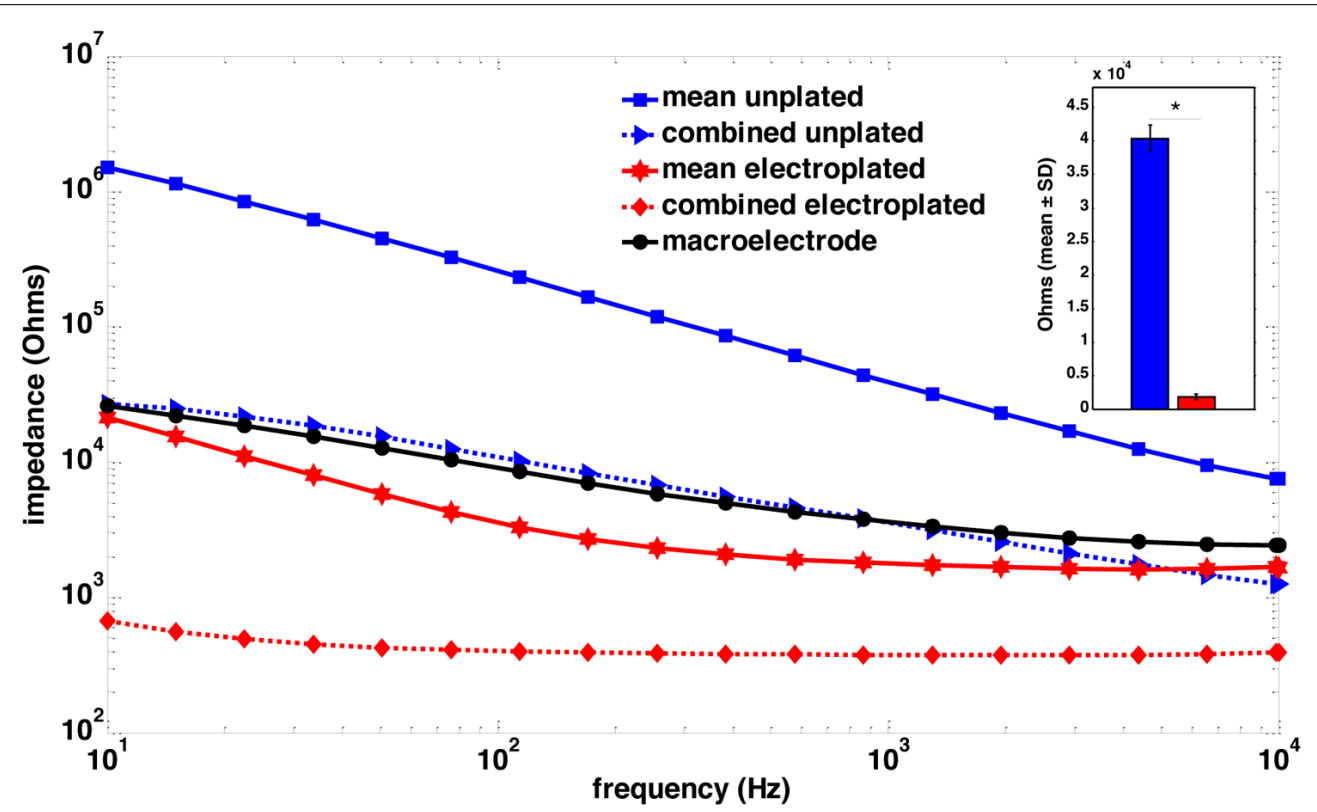

FIGURE 2 | Impedance spectroscopy of macroelectrode, microelectrode array and sonicoplated microelectrode array. Impedance spectra of a single macroelectrode (black), the mean impedance of a plated (red) and an unplated (blue) microelectrode array, and the combined impedance of 15 plated (red, dotted) and unplated (blue, dotted) microelectrodes that were connected in parallel for stimulation. The inset shows a bar graph representation of the mean $\pm \mathrm{SD}$ of the impedance plots at $1 \mathrm{kHz}$, of the 15 microelecrodes before (blue) and after (red) electroplating. ${ }^{*} P<0.05$. performed $4 \mathrm{~h}$ of continuous stimulation (Saryyeva et al., 2011) similar to the methods in the current study. The remaining rats in each group served as controls and did not receive any stimulation. Electrical stimulation was delivered using our custom-built open-source electrophysiology suite, NeuroRighter (Rolston et al., 2009). In cases where the microelectrode array was stimulated, $25 \mathrm{~Hz}$ pulses were delivered synchronously through the electrodes. Both the macroelectrode and the MEA electrodes were insulated except at the tip. After $4 \mathrm{~h}$ of implantation, electrodes were slowly removed from the brain.

\section{IMMUNOHISTOCHEMISTRY}

Following electrode (macro, micro, or sonicoplated micro) removal from the brain, each rat was deeply anesthetized with a lethal dose of Euthasol (130 mg/kg), injected intraperitoneally, and then perfused intracardially with $0.9 \% \mathrm{NaCl}$, followed with $4 \%$ paraformaldehyde in $0.1 \mathrm{M}$ phosphate buffered saline at $\mathrm{pH} 7.2$ (PBS) for $15 \mathrm{~min}$ at a rate of $20 \mathrm{ml}$ per min. Brains were removed and cryoprotected in $30 \%$ sucrose at $4^{\circ} \mathrm{C}$, and the region spanning the entire electrode site sectioned in the horizontal plane at $50 \mu \mathrm{m}$ thickness using a freezing microtome, collected in series of 4 in PBS, and rinsed in PBS. To identify the number and identity of cells activated by the electrical stimulation, double immunofluorescence labeling for the immediate early gene, c-fos (Dragunow and Faull, 1989), and the neuronal marker, NeuN (Mullen et al., 1992) was performed. Free-floating sections were rinsed in PBS, blocked in 5\% normal donkey serum (NDS) and $0.1 \%$ Triton-X100 for $30 \mathrm{~min}$ and rinsed in PBS. After rinses in PBS, sections were incubated overnight at $4^{\circ} \mathrm{C}$ in rabbit anti-c-fos (1:5000; Calbiochem) and mouse anti-NeuN (1:1000; Millipore) in PBS containing 1\% NDS. Sections were rinsed in PBS and incubated in Alexa 594-conjugated donkey anti-rabbit (1:1000; Jackson Immunoresearch) and Alexa 488-conjugated donkey antimouse (1:1000; Jackson Immunoresearch) in 1\% NDS for $1 \mathrm{~h}$. All sections were additionally counterstained by incubation with 4',6-diamidino-2-phenylindole (DAPI) that labels all cell nuclei. Sections were rinsed in PBS, and then mounted on glass slides with Fluoromount-G mounting medium (SouthernBiotech) for fluorescence microscopy. For each double-label experiment, controls included omission of one or both primary antibodies. Sections were visualized using a Nikon eclipse E400 microscope equipped with three fluorescent cubes, a monochrome and color digital camera and Nikon BR software (Nikon Instruments Inc., Melville, NY, USA). For each brain at least 2 series were stained and images corresponding to the tip of the electrodes were used for counting.

\section{CELL COUNTING}

In the horizontal sections $(50 \mu \mathrm{m})$ at the tip of the electrode track, c-fos $+/ \mathrm{NeuN}+$ cells surrounding the track were counted using ImageJ and compared between the various stimulation treatments. NeuN and DAPI staining was used to confirm the location of electrodes. Only those electrodes that resided within the hippocampal cell layers were taken into consideration for this study, other electrodes were ignored. Microelectrodes used in this study were separated by $175 \mu \mathrm{m}$, but even with careful and slow implantation, they tended to deflect ending closer or farther than $175 \mu \mathrm{m}$. Circles in increments of $25 \mu \mathrm{m}$ in radius were drawn around the electrode tracks in each case and the number of c-fos $+/ \mathrm{NeuN}+$ cells were counted within each concentric circle 
pair in each type of electrode implanted condition (macro, micro, sonicoplated micro; stimulated, unstimulated). With microelectrode array implantation, $\mathrm{c}$-fos $+/ \mathrm{NeuN}+$ cells were assigned to the electrode that was closest to the cell. Cell counting was performed until two consecutive circles with no c-fos $+/ \mathrm{NeuN}+$ cells were encountered. For computing neuronal activation density, the number of neurons counted within each concentric circle pair was divided by the volume of tissue over which they were counted ( $h=50 \mu \mathrm{m}$ for these sections). Test for significance was performed using student's $t$-test.

\section{RESULTS}

\section{IMMUNOHISTOCHEMISTRY STAINING OF ELECTRICALLY STIMULATED} AND CONTROL SECTIONS

Whether the rats were implanted with a macroelectrode, a microelectrode array or a sonicoplated microelectrode array, electrical stimulation resulted in c-fos expression limited to a region immediately surrounding the electrode track, suggesting that electrical stimulation has a limited radius of activation in the dorsal hippocampus (Figure 3). Most of the c-fos + cells were also NeuN+. Local to the site of implantation, $\mathrm{c}$-fos + and NeuN- cells were also seen in some of the control and stimulated cases. Co-staining for glial cells was not performed, limiting further analysis of these c-fos $+/ \mathrm{NeuN}-$ cells.

In rats implanted with a macroelectrode or a microelectrode array but not electrically stimulated, no $\mathrm{c}$-fos $+/ \mathrm{NeuN}+$ was detected surrounding the electrode tracks (Figure 3). These results confirm that it is the electrical stimulation and not the process of electrode implantation itself that is responsible for the increased neuronal c-fos expression seen in the stimulated animals. Dorsal hippocampal sections contralateral to the site of implantation and stimulation also were not c-fos+ in all three cases of stimulation (macro, micro and sonicoplated micro). This suggests that c-fos activation is contained within the hemisphere that received the electrical stimulation.

\section{NEURONAL ACTIVATION DISTRIBUTION}

As expected, macroelectrodes produced the largest activation radius, followed by sonicoplated microelectrodes and then unplated microelectrodes (Figure 4A). When stimulated at $25 \mathrm{~Hz}, \pm 1 \mathrm{~V}$, for $4 \mathrm{~h}$, macroelectrodes had a maximum radius of activation of $200 \mu \mathrm{m}$ and single microelectrodes had radius of activation of $100 \mu \mathrm{m}$. Sonicoplated microelectrodes had an increased radius of activation of $150 \mu \mathrm{m}$. This was presumably due to their reduced impedance, passing more current at the same fixed voltage. The control cases, where electrodes were implanted but no stimulation was performed, had no c-fos $+/ \mathrm{NeuN}+$ cells (Figure 3). Interestingly, the sonicoplated microelectrodes had significantly higher activation density $(P<0.05)$ in the first $25 \mu \mathrm{m}$ concentric cylindrical volume (height of section $50 \mu \mathrm{m}$ ) around the electrode track, when compared to unplated microand macroelectrodes (Figure 4B). While both microelectrodes had high activation densities in the first concentric cylindrical volume surrounding the electrode track, this rapidly falls with distance, whereas the macroelectrodes had a more linearly decreasing activation density pattern with increasing distance from electrode track.

\section{NEURONAL ACTIVATION FRACTION AND TOTAL NUMBER OF NEURONS ACTIVATED}

The cumulative activation Figure 5A shows that with macroelectrode stimulation, $50 \%$ of activated neurons $\left(\mathrm{AN}_{50}\right)$ were within a radius of $50.7 \mu \mathrm{m}$ from the electrode track and $90 \%\left(\mathrm{AN}_{90}\right)$ were within a radius of $144.7 \mu \mathrm{m}$. At the other extreme, sonicoplated microelectrodes $\mathrm{AN}_{50}$ was $38.3 \mu \mathrm{m} \mathrm{AN}_{90}$ was $92.7 \mu \mathrm{m}$, with intermediate values for the unplated microelectrode $\left(\mathrm{AN}_{50}, 25 \mu \mathrm{m}\right.$; $\left.\mathrm{AN}_{90}, 70 \mu \mathrm{m}\right)$. A single macroelectrode activated $30.25 \pm 3.95$ neurons surrounding the electrode track in the dorsal hippocampus, in one $50 \mu \mathrm{m}$ brain section compared to $5.2 \pm 0.84$ neurons with a single microelectrode. Sonicoplating resulted in a $52.7 \%$ increase in the number of neurons activated $(11 \pm 1.41)$. In all the unstimulated controls, the number of c-fos+/NeuN+ was not statistically different from background c-fos activation levels (Figure 5B)

\section{NEURONAL ACTIVATION WITH MICROELECTRODE ARRAYS}

In cases where more than one microelectrode from the implanted microelectrode array ended within the pyramidal cell layer of dorsal hippocampus, the number of $\mathrm{c}$-fos $+/ \mathrm{NeuN}+$ cells increased linearly with the number of electrodes within the cell layer (Figure 6A). If we extrapolate these results (Figure 6B), it would take fewer than 6 unplated microelectrodes (at $33 \mu \mathrm{m}$ diameter they would occupy $28 \%$ volume compared to a macroelectrode) or fewer than 3 sonicoplated microelectrodes ( $13.3 \%$ volume compared to macroelectrode) to activate an equal number of neurons as a single macroelectrode ( $150 \mu \mathrm{m}$ diameter). Alternatively, with 20 unplated or sonicoplated microelectrodes (which would occupy less volume compared to a single macroelectrode), 3.5 or 7.5 times more neurons would be activated when compared to a single macroelectrode.

\section{DISCUSSION}

Using c-fos immunohistochemistry, we have compared the radius of activation and the activation density following electrical stimulation through a macroelectrode, a microelectrode array and an electroplated microelectrode array in the dorsal hippocampus. A macroelectrode has an activation radius of $200 \mu \mathrm{m}$, a microelectrode has an activation radius of $100 \mu \mathrm{m}$ and an electroplated microelectrode has an activation radius of $150 \mu \mathrm{m}$. Thus, a microelectrode array approach could be used when precise stimulation of narrow cell layers, such as the pyramidal cells layer of the CA1 and CA3 regions of the hippocampus is desired. By targeting unplated or electroplated microelectrodes to certain cell layers, stimulation of structures outside these targets can be minimized. The activation radius numbers presented here would help in determining the spacing between microelectrodes in the microelectrode array. One method of achieving precise targeting of microelectrodes to specific cell layers would be through the use of movable microelectrodes (Rolston et al., 2011) whose depth can be individually adjusted using microdrives (Keating and Gerstein, 2002). Using a macroelectrode whose diameter is larger than these targets would lead to stimulation of structures outside the target, giving rise to undesired side effects (Hariz, 2002). 


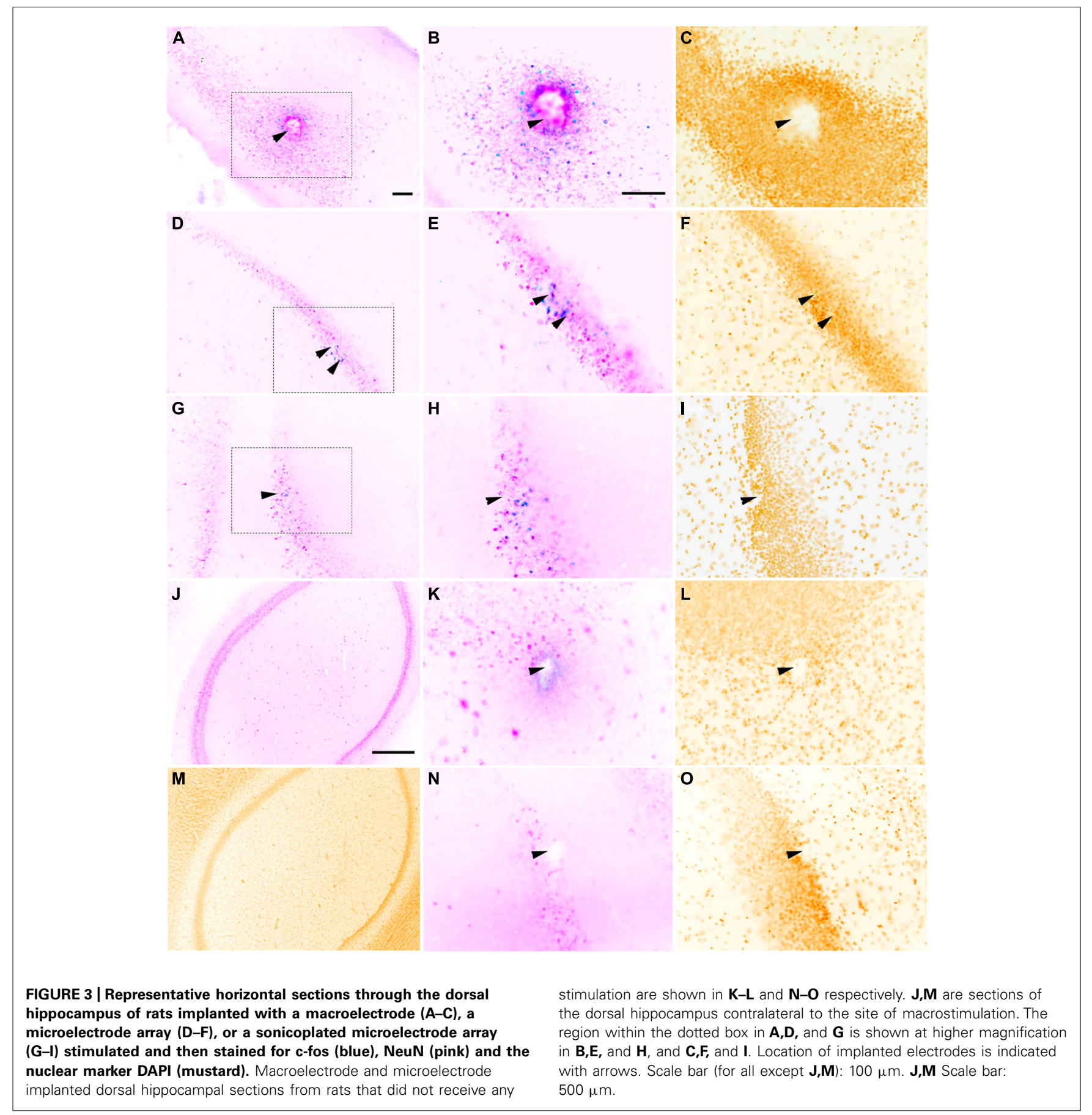

The macroelectrode and the microelectrode array used in this study are from different manufacturers and are made of different material. The macroelectrode was made of stainless steel with polyimide insulation, whereas the microelectrodes were made of tungsten with polyimide insulation and the electroplated material was platinum black. These materials have different charge storage capacities (Merrill etal., 2005) and hence may employ different degrees of capacitive vs. faradaic charge transfer mechanisms (Merrill et al., 2005; Cogan, 2008). Therefore, the differences seen here between the three stimulation cases may arise not only due to the differences in their geometry, but also due to differences in their material composition. We note here that it is common for macroelectrodes to be built from material such as the stainless steel (Gimsa et al., 2005) that have lower charge storage capacity. Metals such as tungsten, platinum or platinum-iridium have higher charge storage capacities and are the popular choice for making microelectrodes (Stoney et al., 1968). The larger size of the macroelectrode gives it sufficient surface area to inject large currents safely (Mccreery etal., 1990). While we acknowledge that a direct 

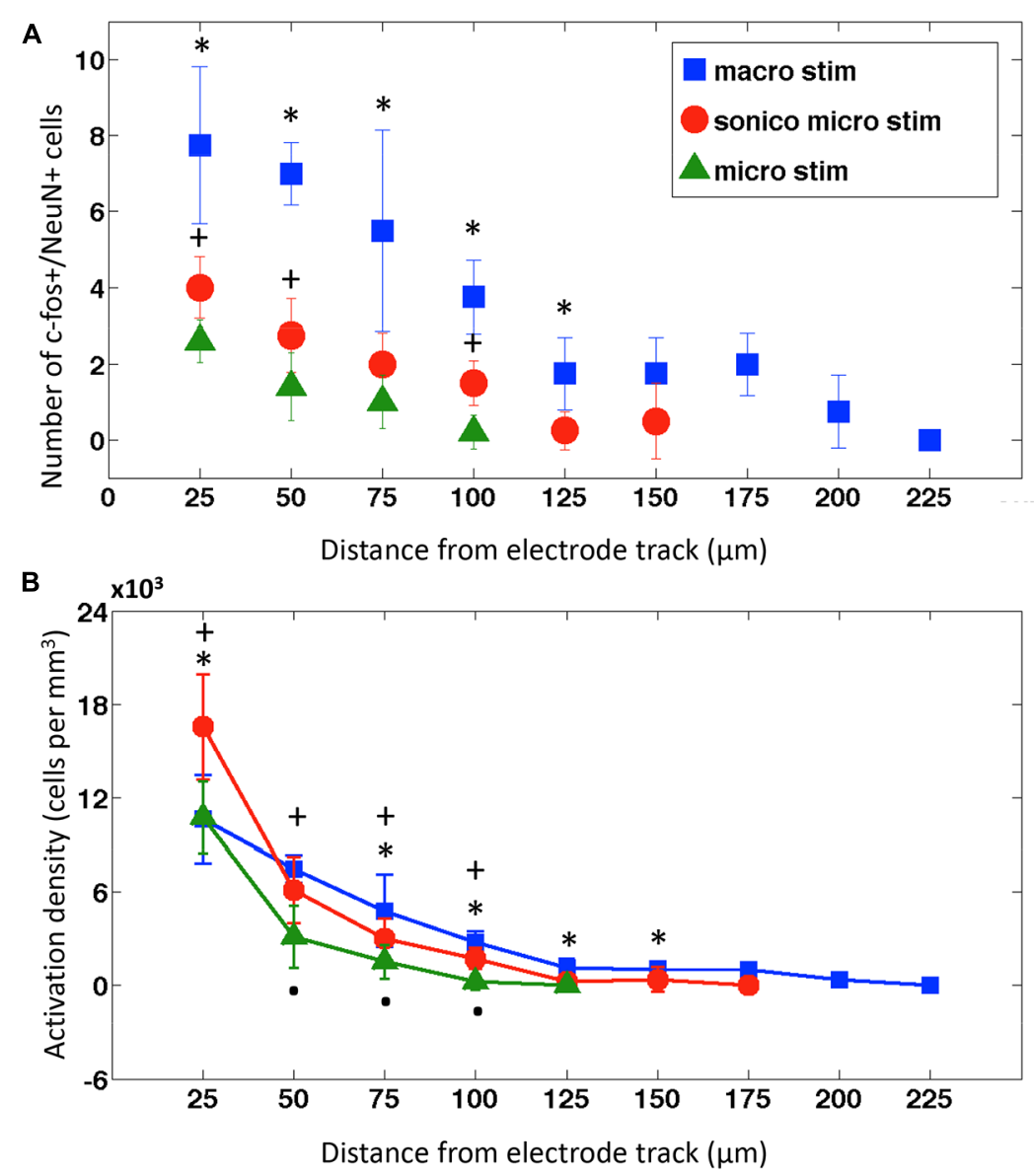

FIGURE 4 | Neuronal activation distribution around electrode tracks. (A) Mean \pm SD of c-fos expressing neurons within concentric circles in $25 \mu \mathrm{m}$ radius increments surrounding implanted and stimulated macroelectrode (macro; blue squares, $n=4$ ), sonicoplated microelectrode (sonico micro; red circles, $n=4$ ) and microelectrode electrodes (micro; green triangles, $n=4)$. ${ }^{*} P<0.05$ between macroelectrode, sonicoplated microelectrode, and unplated microelectrode (where data is present).
$+P<0.05$ between sonicoplated and unplated microelectrode. (B) Mean \pm $\mathrm{SD}$ neuronal activation density (number of c-fos $+/ \mathrm{NeuN}+$ cells $/ \mathrm{m}^{3}$ ) with macroelectrode (macro), sonicoplated microelectrode (sonico micro) and microelectrode (micro) stimulation around the electrode tracks; ${ }^{*} P<0.05$ between macroelectrode and sonicoplated microelectrode; ${ }^{+} P<0.05$ between sonicoplated and unplated microelectrode; $P<0.05$ between unplated microelectrode and macroelectrode.
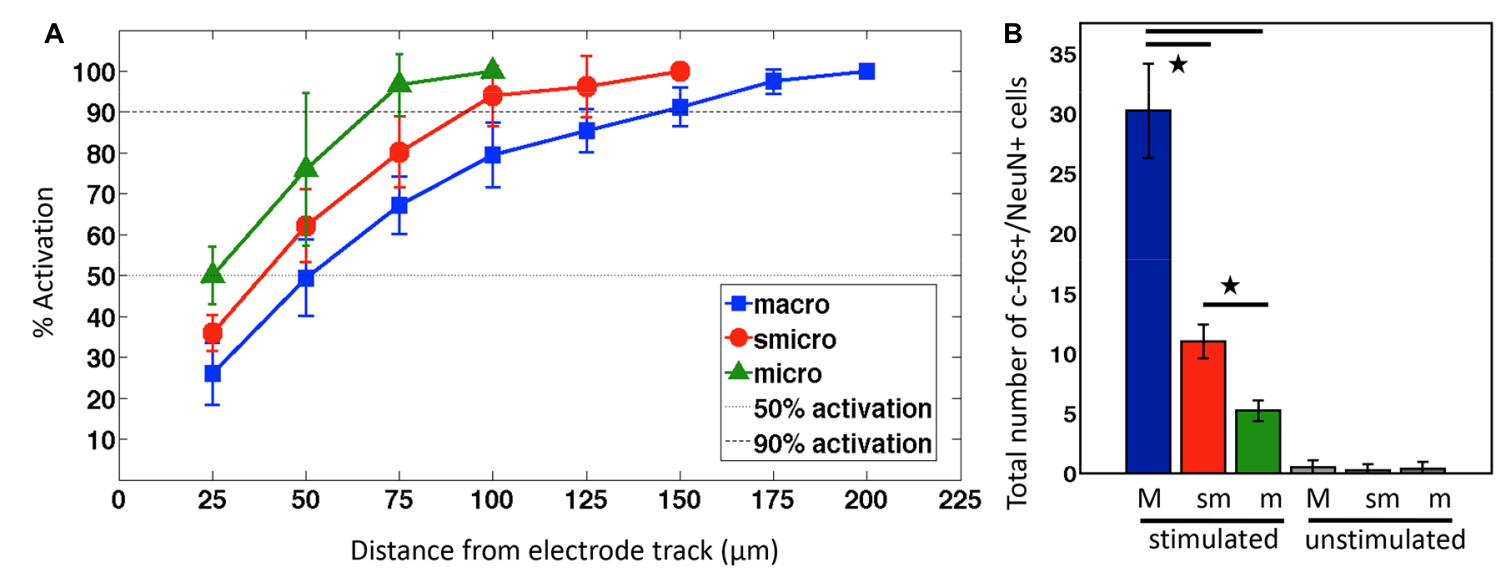

FIGURE 5 | Neuronal activation density and total number of neurons activated. (A) Mean \pm SD percentage of neuronal activation $\%$ in $25 \mu \mathrm{m}$ radius increments surrounding implanted and stimulated electrodes. (B) Bar graphs showing the mean $\pm \mathrm{SD}$ number of $\mathrm{c}$-fos+/NeuN+ cells with macroelectrode (M), sonicoplated microelectrode (sm), or unplated microelectrode $(\mathrm{m})$, with and without stimulation. ${ }^{*} P<0.05$. 


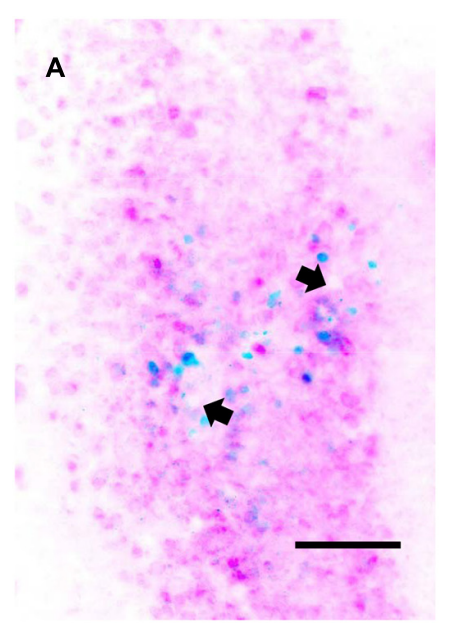

FIGURE 6 | Neuronal activation with several microelectrodes.

(A) Representative horizontal section through the dorsal hippocampus of a rat implanted with a microelectrode array. The image shows two microelectrode sites (depicted with arrows) ending within the hippocampal pyramidal cell layer. The section is stained for c-fos (blue) and NeuN (pink).
Scale bar: $100 \mu \mathrm{m}$. (B) Estimated neuronal activation in $50 \mu \mathrm{m}$ brain sections with multiple unplated and sonicoplated microelectrodes (micro, smicro respectively) implanted in the hippocampal cell layer. The horizontal black dotted line shows the mean number of neurons activated by a single macroelectrode for comparison. comparison of the effects of increasing only the size of electrodes on the activation radius would require the electrodes to be made of the same material, a study of that nature would have less practical relevance since materials such as platinumiridium are rarely used to make the macroelectrodes used in animal studies.

Only one electrical stimulation parameter $( \pm 1 \mathrm{~V}, 400 \mu \mathrm{s} /$ phase, biphasic square pulses at $25 \mathrm{~Hz}$ ) was tested in this paper. Since different populations of neurons within the hippocampus have a preference to fire when stimulated at distinct frequencies (For example Pike et al., 2000 shows that pyramidal cells have a lower frequency preference while fast spiking interneurons prefer higher frequencies), we anticipate that stimulating at higher/lower frequencies and voltages will excite different populations and numbers of neurons (Wagenaar et al., 2004). For example, a study performed in the pedunculopontine nucleus in the rat 6-hydroxydopamine (6-OHDA) Parkinson's disease model using c-fos immunohistochemistry showed that $25 \mathrm{~Hz}$ stimulation activated more neurons when compared to $130 \mathrm{~Hz}$ stimulation (Saryyeva et al., 2011).

In chronic implantation studies, glial encapsulation of the implanted electrode increases the distance of the target neurons from the implanted electrode (Griffith and Humphrey, 2006; Bewernick et al., 2010). Although we did not look into the effects of gliosis on the number of neurons activated, we hypothesize that this process would cause a steady decrease in neuronal activation over time in voltage controlled stimulation studies due to increased impedance of the tissue-electrode interface (Butson et al., 2006). Additional empirical studies should address the effects of glial encapsulation on neuronal activation. In chronic implantation experiments, changes in impedance over time should be closely monitored and stimulation parameters should be adjusted to account for this increased impedance to achieve a better control on neural activation, although this is compensated directly in current-controlled approaches. Using a closed-loop electrophysiology setup [e.g., NeuroRighter (Newman et al., 2012)] will greatly help in automating this process.

As discussed above (see Results), the implantation of the macroelectrode used in this study ( $150 \mu \mathrm{m}$ diameter) would cause 20.67 times the tissue damage of implantation of a single microelectrode (33 $\mu \mathrm{m}$ diameter). For human DBS electrodes, which are typically $1.27 \mathrm{~mm}$ in diameter, this ratio would be much larger. By positioning microelectrodes sufficiently close within a given target, more neurons can be activated than using a single macroelectrode while causing less tissue damage.

\section{ACKNOWLEDGMENTS}

This work was supported by the CURE Foundation, NSF EFRI 1238097, Wallace H. Coulter foundation. The Schlumberger Faculty for the Future fellowship supported Sharanya Arcot Desai. The authors wish to thank members of the Potter and Gross labs for their valuable suggestions.

\section{REFERENCES}

Benabid, A. L., Chabardes, S., Mitrofanis, J., and Pollak, P. (2009). Deep brain stimulation of the subthalamic nucleus for the treatment of Parkinson's disease. Lancet Neurol. 8, 67-81. doi: 10.1016/S1474-4422(08) 70291-6

Bewernick, B. H., Hurlemann, R., Matusch, A., Kayser, S., Grubert, C., Hadrysiewicz, B., et al. (2010). Nucleus accumbens deep brain stimulation decreases ratings of depression and anxiety in treatment-resistant depression. Biol. Psychiatry 67, 110-116. doi: 10.1016/j.biopsych.2009.09.013

Butson, C. R., Cooper, S. E., Henderson, J. M., Wolgamuth, B., and McIntyre, C. C. (2011). Probabilistic analysis of activation volumes generated during deep brain stimulation. Neuroimage 54, 2096-2104. doi: 10.1016/j.neuroimage.2010. 10.059

Butson, C. R., Maks, C. B., and McIntyre, C. C. (2006). Sources and effects of electrode impedance during deep brain stimulation. Clin. Neurophysiol. 117, 447-454. doi: 10.1016/j.clinph.2005.10.007

Chaturvedi, A., Butson, C. R., Lempka, S. F., Cooper, S. E., and McIntyre, C. C. (2010). Patient-specific models of deep brain stimulation: influence of field 
model complexity on neural activation predictions. Brain Stimul. 3, 65-67. doi: 10.1016/j.brs.2010.01.003

Cogan, S. F. (2008). Neural stimulation and recording electrodes. Annu. Rev. Biomed. Eng. 10, 275-309. doi: 10.1146/annurev.bioeng.10.061807.160518

da Silva, J. C., Scorza, F. A., Nejm, M. B., Cavalheiro, E. A., and Cukiert, A. (2014). c-FOS expression after hippocampal deep brain stimulation in normal rats. Neuromodulation 17, 213-217. doi: 10.1111/ner.12122

Desai, S. A., Rolston, J. D., Guo, L., and Potter, S. M. (2010). Improving impedance of implantable microwire multi-electrode arrays by ultrasonic electroplating of durable platinum black. Front. Neuroeng. 3:5. doi: 10.3389/fneng.2010.00005

Dragunow, M., and Faull, R. (1989). The use of c-fos as metabolic marker in neuronal pathway tracing. J. Neurosci. Methods 29, 261-265. doi: 10.1016/01650270(89)90150-7

Ferguson, J. E., Boldt, C., and Redish, A. D. (2009). Creating low-impedance tetrodes by electroplating with additives. Sens. Actuators A Phys. 156, 388-393. doi: 10.1016/j.sna.2009.10.001

Gimsa, J., Habel, B., Schreiber, U., van Rienen, U., Strauss, U., and Gimsa, U. (2005). Choosing electrodes for deep brain stimulation experimentselectrochemical considerations. J. Neurosci. Methods 142, 251-265. doi 10.1016/j.jneumeth.2004.09.001

Greenberg, B. D., Malone, D. A., Friehs, G. M., Rezai, A. R., Kubu, C. S., Malloy, P. F., et al. (2006). Three-year outcomes in deep brain stimulation for highly resistant obsessive-compulsive disorder. Neuropsychopharmacology 31, 2384-2393. doi: 10.1038/sj.npp.1301165

Griffith, R. W., and Humphrey, D. R. (2006). Long-term gliosis around chronically implanted platinum electrodes in the Rhesus macaque motor cortex. Neurosci. Lett. 406, 81-86. doi: 10.1016/j.neulet.2006.07.018

Grill, W. M. (1999). Modeling the effects of electric fields on nerve fibers: influence of tissue electrical properties. IEEE Trans. Biomed. Eng. 46, 918-928. doi: $10.1109 / 10.775401$

Hariz, M. I. (2002). Complications of deep brain stimulation surgery. Mov. Disord. 17, S162-S166. doi: 10.1002/mds.10159

Helmchen, F., and Denk, W. (2005). Deep tissue two-photon microscopy. Nat. Methods 2, 932-940. doi: 10.1038/nmeth818

Histed, M. H., Bonin, V., and Reid, R. C. (2009). Direct activation of sparse, distributed populations of cortical neurons by electrical microstimulation. Neuron 63, 508-522. doi: 10.1016/j.neuron.2009.07.016

Keating, J. G., and Gerstein, G. L. (2002). A chronic multi-electrode microdrive for small animals. J. Neurosci. Methods 117, 201-206. doi: 10.1016/S01650270(02)00115-2

Kumar, R., Lozano, A. M., Kim, Y. J., Hutchison, W. D., Sime, E., Halket, E., et al. (1998). Double-blind evaluation of subthalamic nucleus deep brain stimulation in advanced Parkinson's disease. Neurology 51, 850-855. doi: 10.1212/WNL.51.3.850

Mayberg, H. S., Lozano, A. M., Voon, V., McNeely, H. E., Seminowicz, D., Hamani, C. et al. (2005). Deep brain stimulation for treatment-resistant depression. Neuron 45, 651-660. doi: 10.1016/j.neuron.2005.02.014

Mccreery, D. B., Agnew, W. F., Yuen, T. G., and Bullara, L. (1990). Charge-density and charge per phase as cofactors in neural injury induced by electrical-stimulation. IEEE Trans. Biomed. Eng. 37, 996-1001. doi: 10.1109/10.102812

McIntyre, C. C., Mori, S., Sherman, D. L., Thakor, N. V., and Vitek, J. L. (2004a). Electric field and stimulating influence generated by deep brain stimulation of the subthalamic nucleus. Clin. Neurophysiol. 115, 589-595. doi: 10.1016/j.clinph.2003.10.033

McIntyre, C. C., Savasta, M., Kerkerian-Le Goff, L., and Vitek, J. L. (2004b). Uncovering the mechanism(s) of action of deep brain stimulation: activation, inhibition, or both. Clin. Neurophysiol. 115, 1239-1248. doi: 10.1016/j.clinph.2003.12.024

Merrill, D. R., Bikson, M., and Jefferys, J. G. R. (2005). Electrical stimulation of excitable tissue: design of efficacious and safe protocols. J. Neurosci. Methods 141, 171-198. doi: 10.1016/j.jneumeth.2004.10.020

Morgan, J. I., and Curran, T. (1991). Stimulus-transcription coupling in the nervous system: involvement of the inducible proto-oncogenes fos and jun. Annu. Rev. Neurosci. 14, 421-451. doi: 10.1146/annurev.ne.14.030191.002225
Mullen, R. J., Buck, C. R., and Smith, A. M. (1992). Neun, a neuronal specific nuclear-protein in vertebrates. Development 116, 201-211.

Muller, R., Bravo, R., Burckhardt, J., and Curran, T. (1984). Induction of c-fos gene and protein by growth-factors precedes activation of c-myc. Nature 312, 716-720. doi: $10.1038 / 312716 \mathrm{a} 0$

Newman, J. P., Zeller-Townson, R., Fong, M. F., Arcot Desai, S., Gross, R. E., and Potter, S. M. (2012). Closed-Loop, Multichannel experimentation using the opensource neurorighter electrophysiology platform. Front. Neural Circuits 6:98. doi: 10.3389/fncir.2012.00098

Perlmutter, J. S., and Mink, J. W. (2006). Deep brain stimulation. Annu. Rev. Neurosci. 29, 229-257. doi: 10.1146/annurev.neuro.29.051605.112824

Pike, F. G., Goddard, R. S., Suckling, J. M., Ganter, P., Kasthuri, N., and Paulsen, O. (2000). Distinct frequency preferences of different types of rat hippocampal neurones in response to oscillatory input currents. J. Physiol. 529, 205-213. doi: 10.1111/j.1469-7793.2000.00205.x

Rolston, J. D., Desai, S. A., Laxpati, N. G., and Gross, R. E. (2011). Electrical stimulation for epilepsy: experimental approaches. Neurosurg. Clin. N. Am. 22, 425-442. doi: 10.1016/j.nec.2011.07.010

Rolston, J. D., Gross, R. E., and Potter, S. M. (2009). A low-cost multielectrode system for data acquisition enabling real-time closed-loop processing with rapid recovery from stimulation artifacts. Front. Neuroeng. 2:12. doi: 10.3389/neuro.16.012.2009 Rozman, J., Milosev, I., and Jenko, M. (2000). Platinum stimulating electrodes in physiological media. J. Med. Eng. Technol. 24, 123-128. doi: $10.1080 / 03091900050135040$

Saryyeva, A., Nakamura, M., Krauss, J. K., and Schwabe, K. (2011). c-Fos expression after deep brain stimulation of the pedunculopontine tegmental nucleus in the rat 6-hydroxydopamine Parkinson model. J. Chem. Neuroanat. 42, 210-217. doi: 10.1016/j.jchemneu.2011.08.003

Stoney, S. D., Thompson, W. D., and Asanuma, H. (1968). Excitation of pyramidal tract cells by intracortical microstimulation - effective extent of stimulating current. J. Neurophysiol. 31, 659-669.

Velasco, A. L., Velasco, F., Velasco, M., Jiménez, F., Carrillo-Ruiz, J. D., and Castro, G. (2007). The role of neuromodulation of the hippocampus in the treatment of intractable complex partial seizures of the temporal lobe. Acta Neurochir. Suppl. 97(Pt 2), 329-332. doi: 10.1007/978-3-211-33081-4_36

Velasco, F., Velasco, M., Velasco, A. L., Menez, D., and Rocha, L. (2001). Electrical stimulation for epilepsy: stimulation of hippocampal foci. Stereotact. Funct. Neurosurg. 77, 223-227. doi: 10.1159/000064610

Volkmann, J., Moro, E., and Pahwa, R. (2006). Basic algorithms for the programming of deep brain stimulation in Parkinson's disease. Mov. Disord. 21, S284-S289. doi: 10.1002/mds. 20961

Wagenaar, D. A., Pine, J., and Potter, S. M. (2004). Effective parameters for stimulation of dissociated cultures using multi-electrode arrays. J. Neurosci. Methods 138, 27-37. doi: 10.1016/j.jneumeth.2004.03.005

Wei, X. F., and Grill, W. M. (2009). Analysis of high-perimeter planar electrodes for efficient neural stimulation. Front. Neuroeng. 2:15. doi: 10.3389 /neuro.16.015.2009

Conflict of Interest Statement: The authors declare that the research was conducted in the absence of any commercial or financial relationships that could be construed as a potential conflict of interest.

Received: 12 December 2013; accepted: 19 May 2014; published online: 12 June 2014. Citation: Arcot Desai S, Gutekunst C-A, Potter SM and Gross RE (2014) Deep brain stimulation macroelectrodes compared to multiple microelectrodes in rat hippocampus. Front. Neuroeng. 7:16. doi: 10.3389/fneng.2014.00016

This article was submitted to the journal Frontiers in Neuroengineering.

Copyright (C) 2014 Arcot Desai, Gutekunst, Potter and Gross. This is an open-access article distributed under the terms of the Creative Commons Attribution License (CC $B Y)$. The use, distribution or reproduction in other forums is permitted, provided the original author(s) or licensor are credited and that the original publication in this journal is cited, in accordance with accepted academic practice. No use, distribution or reproduction is permitted which does not comply with these terms. 